\title{
A Facile Self-assembly Synthesis of Hexagonal ZnO Nanosheet Films and Their Photoelectrochemical Properties
}

\author{
Bin Zhang ${ }^{1} \cdot$ Faze Wang ${ }^{1}$ Changqing Zhu ${ }^{1} \cdot{\text { Qiang } \mathrm{Li}^{1} \cdot \text { Jingnan Song }^{1} \cdot \text { Maojun Zheng }}^{1,2} \cdot \mathrm{Li} \mathrm{Ma}^{3} \cdot$ \\ Wenzhong Shen ${ }^{1,2}$
}

Received: 13 July 2015/Accepted: 23 September 2015/Published online: 15 October 2015

(C) The Author(s) 2015. This article is published with open access at Springerlink.com

\begin{abstract}
Here, large-scale and uniform hexagonal zinc oxide $(\mathrm{ZnO})$ nanosheet films were deposited onto indium tin oxide (ITO)-coated transparent conducting glass substrates via a facile galvanic displacement deposition process. Compared with other commonly used solution methods, this process avoids high temperature and electric power as well as supporting agents to make it simple and cost-effective. The as-fabricated $\mathrm{ZnO}$ nanosheet films have uniform hexagonal wurtzite structure. The photoelectrochemical (PEC) cell based on $\mathrm{ZnO}$ nanosheet film/ITO photoelectrode was also fabricated and its performance was improved by optimizing the solution concentration. A higher photocurrent density of $\sim 500 \mu \mathrm{A} \mathrm{cm}^{-2}$ under AM $1.5 \mathrm{G}$ simulated illumination of $100 \mathrm{~mW} \mathrm{~cm}{ }^{-2}$ with zero bias potential (vs. $\mathrm{Ag} / \mathrm{AgCl}$ electrode) was obtained, which may ascribe to the increased surface-to-volume ratio of disordered $\mathrm{ZnO}$ nanosheet arrays. Our developed method may be used to deposit other oxide semiconductors, and the $\mathrm{ZnO}$ nanosheet film/ITO PEC cell can be used to design low-cost optoelectronic and photoelectrochemical devices.
\end{abstract}

Keywords Zinc oxide $\cdot$ Nanosheet film $\cdot$ Self-assemble $\cdot$ Galvanic displacement method $\cdot$ Photoelectrochemical property

\section{Introduction}

Over the past decades, there has been an increasing scientific interest in oxide semiconductors (such as $\mathrm{TiO}_{2}$, $\mathrm{ZnO}, \mathrm{Fe}_{2} \mathrm{O}_{3}, \mathrm{CuO}, \mathrm{NiO}$, and so on) [1-3], because of their numerous potential technological applications, including photovoltaic device [4], lithium ion battery [5], photocatalysis, and optoelectronic device [6, 7]. Among the

Maojun Zheng

mjzheng@sjtu.edu.cn

$1 \quad$ Key Laboratory of Artificial Structures and Quantum Control (Ministry of Education), Department of Physics and

Astronomy, Shanghai Jiao Tong University,

Shanghai 200240, People's Republic of China

2 Collaborative Innovation Center of Advanced

Microstructures, Nanjing University, Nanjing 210093,

People's Republic of China

3 School of Chemistry \& Chemical Technology, Shanghai Jiao Tong University, Shanghai 200240,

People's Republic of China oxide semiconductors, $\mathrm{ZnO}$ as a prototypical $n$-type conducting oxide has attracted considerable attentions for wide usages in piezoelectric device, ultraviolet optoelectronics detectors [8,9], low-cost dye-sensitized solar cells [10], gas sensors [11, 12], photocatalysis, and photoelectrochemical (PEC) devices [13, 14]. Most of these applications are based on the advantages of its abundance, low cost, non-toxicity, chemical stability and the possibility of growing ordered nanostructures, and strong exciton binding energy [15]. Especially, nanostructured $\mathrm{ZnO}$ exhibits enhanced performance and provided an ideal system to study the influence of surface effects and interface science on photoelectrochemical properties due to their large surface-to-volume ratios [16-18].

To date, $\mathrm{ZnO}$ and other nanostructured materials have been assembled and studied by various methods and means [19-22], including magnetron sputtering [23], chemical vapor deposition [24], hydrothermal process [25], electrochemical deposition [26-28], electroless deposition [29, 30], and other combination of methods [31]. Among all these techniques, electroless deposition presents several 
advantages such as low cost, large-scale deposition, and low-temperature processing. Here, we explored a facile solution-based galvanic displacement deposition technique to self-assembly synthesis uniform hexagonal $\mathrm{ZnO}$ nanosheet film on ITO glass substrate under ambient conditions. $\mathrm{ZnO}$ nanosheet film/ITO PEC cell and its photoelectrochemical property were also investigated.

\section{Experimental Details}

\subsection{Synthesis of the ZnO Nanosheet Films}

Compared with other common electrodeposition methods, an electroless deposition process was employed to fabricate $\mathrm{ZnO}$ nanosheets. A typical galvanic cell system with two half-cells (A and B) was used to generate a current by coupling oxidation and reduction reactions in a spontaneous process, in which the A cell solution is $5-15 \mathrm{mM}$ $\mathrm{ZnSO}_{4}$ and the B cell solution is $0.25 \mathrm{M} \mathrm{NaOH}$. The two half-cells were connected by a porous salt bridge that supplied ions to maintain charge neutrality during current flow. The galvanic cell deposition system is composed of $\mathrm{Al}$ sheet (99.99\% purity) and ITO conducting glass (sheet resistance of $10 \Omega \mathrm{cm}^{-2}$ ), which acted as anode and cathode, respectively. The two electrodes were short-circuited externally through a metal copper wire. Before deposition, $4 \mathrm{~cm} \times 2 \mathrm{~cm} \mathrm{Al}$ sheet and ITO glass were, respectively, cleaned in acetone, ethanol, and deionized water for $5 \mathrm{~min}$. Then, the $\mathrm{Al}$ sheet was immerged into A cell solution and the ITO glass was immerged into B cell solution without stirring and oxygen gas bubbling at room temperature. In order to obtain higher crystal quality, the as-prepared samples were annealed at $550{ }^{\circ} \mathrm{C}$ for $60 \mathrm{~min}$ with the increasing rate of $10^{\circ} \mathrm{C} \mathrm{min}^{-1}$ in an air atmosphere.

\subsection{Characterization}

The surface morphology of the as-deposited $\mathrm{ZnO}$ nanosheet films was obtained by field emission scanning electron microscopy (FE-SEM; FEI Sirion 200, Holland). A D8 ADVANCE DA VINCI X-ray diffractometer (XRD, Bruker, German) was employed to verify the crystal structure of the samples using $\mathrm{Cu} K \alpha$ radiation $(\lambda=0.15418 \mathrm{~nm})$ with a scanning rate of $5^{\circ} \mathrm{min}^{-1}$. The photoluminescence (PL) spectrum of the as-resulting $\mathrm{ZnO}$ films was obtained using the Jobin-Yvon LabRam HR 800 UV system with a $325-\mathrm{nm}$ laser at room temperature. The UV-Vis spectra of the $\mathrm{ZnO}$ samples were obtained through UV-Vis spectrophotometer (PerkinElmer Lambda 950, America).

\subsection{PEC Cell Preparation and PEC Characterization}

PEC cell was fabricated by placing a copper wire onto a bare portion of the ITO conducting substrate and securing with high-purity silver conducting glue. Then, the part active area of $\mathrm{ZnO}$ nanosheet films was sealed with epoxy resin leaving an exposed working electrode surface area of $1 \mathrm{~cm} \times 1 \mathrm{~cm}$. An electrochemical workstation (Princeton Applied Research, PARSTAT 4000, America) was used to study the photoelectrochemical property of the samples. The photoelectrochemical experiment was performed in a conventional three electrode, in which the resulting $\mathrm{ZnO}$ nanosheet film/ITO substrate acted as working electrode (illuminating area of $1 \mathrm{~cm}^{2}$ ), a platinum net (surface area of $1 \mathrm{~cm}^{2}$ ) as counter electrode, and an $\mathrm{Ag} / \mathrm{AgCl}$ as reference electrode. The PEC experiments were carried out in a mixture solution of $0.35 \mathrm{M} \mathrm{Na} 2 \mathrm{~S}$ and $0.25 \mathrm{M} \mathrm{Na}_{2} \mathrm{SO}_{3}$ under AM $1.5 \mathrm{G}\left(100 \mathrm{~mW} \mathrm{~cm}{ }^{-2}\right)$ simulated illumination, which was provided by a $300 \mathrm{~W}$ xenon lamp (Beijing Perfectlight Technology, PLS-SXE300C, China) equipped with an AM 1.5 filter. The illumination intensity was measured with a solar simulator spectroradiometer (EKO instrument, LS-100, Japan).

\section{Results and Discussion}

The schematic drawing of the experimental setup used for the fabrication $\mathrm{ZnO}$ nanosheet films is shown in Fig. 1 . When the Al electrode, connected with the ITO glass externally, was dipped into the $\mathrm{NaOH}$ solution, $\mathrm{Al}^{3+}$ ions formed in the solution due to the dissolution of $\mathrm{Al}$ foil. Then, the released electrons moved through the externally short-circuited path to the ITO electrode. At the same time, the electron prompted the basic electrochemical reduction of oxygen $\left(\mathrm{O}_{2}\right)$ in the aqueous solution, and then led to the formation of $\mathrm{OH}^{-}$ions on ITO substrate surface. Finally,

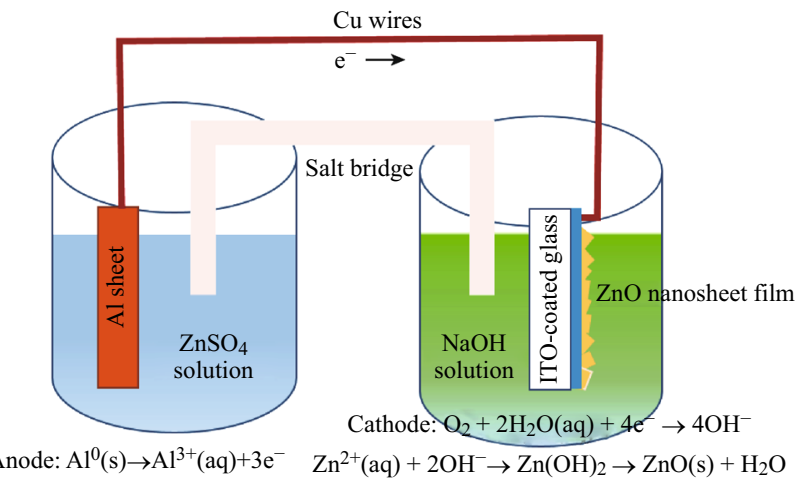

Fig. 1 The schematic drawing of the experimental setup used for the fabrication of hexagonal $\mathrm{ZnO}$ nanosheet films 
the $\mathrm{Zn}^{2+}$ ions in the solution were attracted by the corresponding $\mathrm{OH}^{-}$ions on the ITO surface, and an intermediate $\mathrm{Zn}(\mathrm{OH})_{2}$ was formed and rapidly converted to $\mathrm{ZnO}$. The growth mechanism of $\mathrm{ZnO}$ nanosheet film has similar electrochemical reaction with the electrodeposition [32]. The reactions may be as follows:

Anode: $\mathrm{Al}^{0}(\mathrm{~s}) \rightarrow \mathrm{Al}^{3+}(\mathrm{aq})+3 \mathrm{e}^{-}$

Cathode: $\mathrm{O}_{2}+2 \mathrm{H}_{2} \mathrm{O}(\mathrm{aq})+4 \mathrm{e}^{-} \rightarrow 4 \mathrm{OH}^{-}$

$\mathrm{Zn}^{2+}(\mathrm{aq})+2 \mathrm{OH}^{-} \rightarrow \mathrm{Zn}(\mathrm{OH})_{2} \rightarrow \mathrm{ZnO}(\mathrm{s})+\mathrm{H}_{2} \mathrm{O}$.

In the process of nanosheet film formation, $\mathrm{ZnO}$ nanocrystals were primarily generated and then they were self-assembled into ordered hexagon nanostructure. These staggered arrangement nanosheet formed $\mathrm{ZnO}$ film in the substrate surface finally. Actually, semiconductor selfassembly is a complex phenomenon that depends on the interplay of several physical factors and competing interactions of different nature. A thorough understanding of the self-assembly mechanism of nanocrystals to organize into ordered nanostructure is one of the keys of future nanoscience [33].

Figure 2 shows FE-SEM images of the top and side view of the hexagonal $\mathrm{ZnO}$ nanosheet films grown on the ITO substrate at 5 and $10 \mathrm{mM} \mathrm{ZnSO}_{4}$ aqueous solution for $2 \mathrm{~h}$, and annealed at $550{ }^{\circ} \mathrm{C}$ for $1 \mathrm{~h}$. One can see that the $\mathrm{ZnO}$ had quite perfect hexagon and large-scale irregular arrangement. The samples shown in Fig. 2a, b were, respectively, grown at $5 \mathrm{mM} \mathrm{ZnSO}_{4}$ solution and $10 \mathrm{mM}$ $\mathrm{ZnSO}_{4}$. It can be seen that the concentration of $\mathrm{ZnSO}_{4}$ aqueous solution plays an important role in the size and thickness of hexagonal $\mathrm{ZnO}$ nanosheets, as well as the surface-to-volume ratios.

Figure 3 shows XRD pattern of the hexagonal $\mathrm{ZnO}$ nanosheet films on ITO by electroless depositing at $7.5 \mathrm{mM} \mathrm{ZnSO}_{4}$ for $2 \mathrm{~h}$ under room temperature and postannealing at $550{ }^{\circ} \mathrm{C}$ for $1 \mathrm{~h}$ in open air conditions. All diffraction peaks correspond to the standard diffraction of a

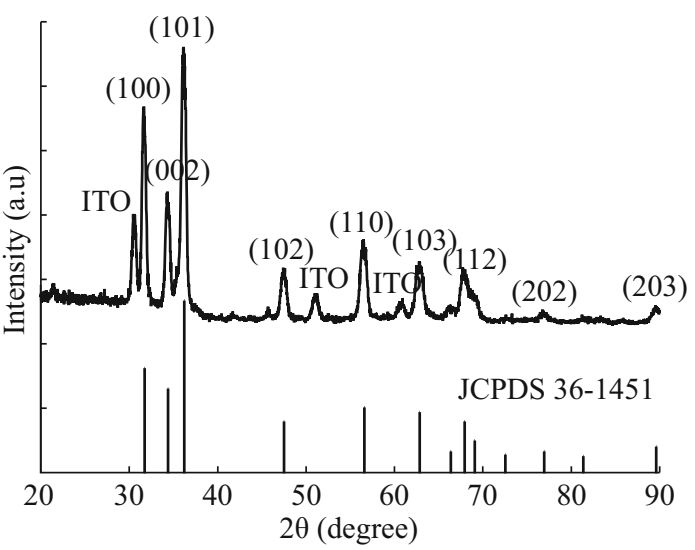

Fig. 3 XRD pattern of the as-annealed hexagonal $\mathrm{ZnO}$ nanosheet film at $550{ }^{\circ} \mathrm{C}$ in open air conditions

hexagonal wurtzite $\mathrm{ZnO}$ crystal (JCPDS 36-1451) [34]. The major diffraction peaks have sharp features, corresponding to the (100), (002), (101), (102), (110), (103), and (112) planes, which is due to the disorder arrangement of $\mathrm{ZnO}$ nanosheets on the ITO. At the same time, the peaks from the ITO conducting substrates were observed as well.

Figure 4 exhibits the representative room temperature $\mathrm{PL}$ spectrum of the $\mathrm{ZnO}$ nanosheet films grown in $7.5 \mathrm{mM}$ $\mathrm{ZnSO}_{4}$ aqueous solution and annealed at $550{ }^{\circ} \mathrm{C}$ for $1 \mathrm{~h}$. A laser with wavelength of $325 \mathrm{~nm}$ was used as the excitation source. The strong UV emission peak at about $390 \mathrm{~nm}$ could be usually attributed to the free exciton emission from the wide band-gap $\mathrm{ZnO}$ [35]. The lower broad peak around $500 \mathrm{~nm}$ is usually considered to be the recombination of a photogenerated hole with the single ionized charged state of the defect in $\mathrm{ZnO}$ and could be related to the surface oxygen vacancies of the $\mathrm{ZnO}$ because the $\mathrm{ZnO}$ nanosheet films have much high surface-to-volume ratios [36]. The PL spectrum result indicates that the as-prepared $\mathrm{ZnO}$ has few defects [37]. The inset image in Fig. 4 shows the UV-Vis absorption spectrum of this sample, indicating
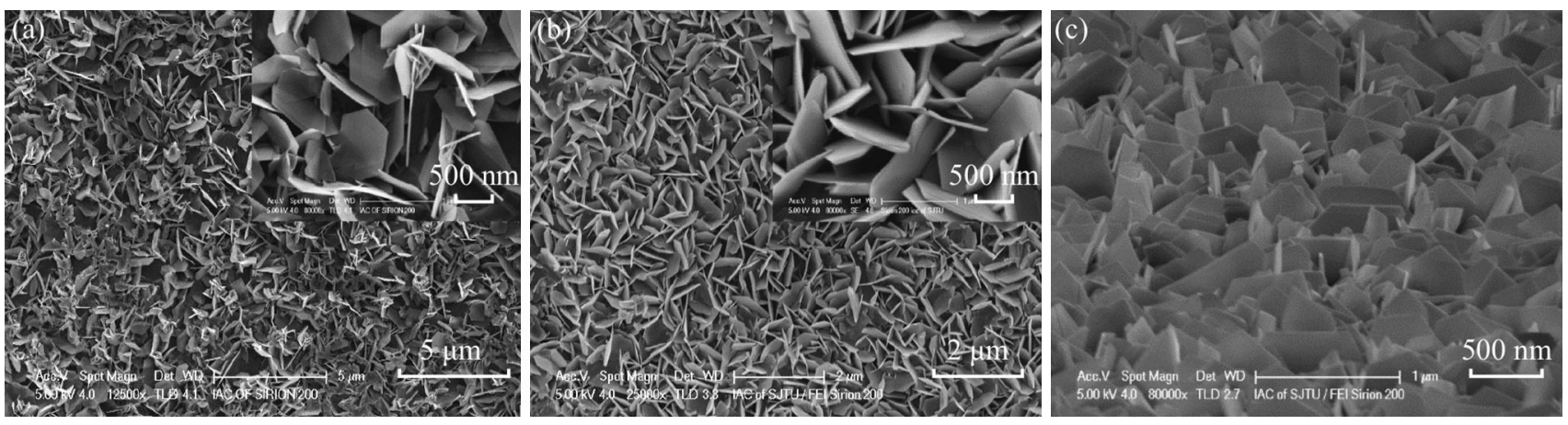

Fig. 2 FE-SEM images of the as-prepared hexagonal $\mathrm{ZnO}$ nanosheet films grown on the ITO-coated glass substrate with different concentrations of $\mathrm{ZnSO}_{4}$. a $5 \mathrm{mM}$ and $\mathbf{b} 10 \mathrm{mM}$, top view. c $10 \mathrm{mM}$, side view 


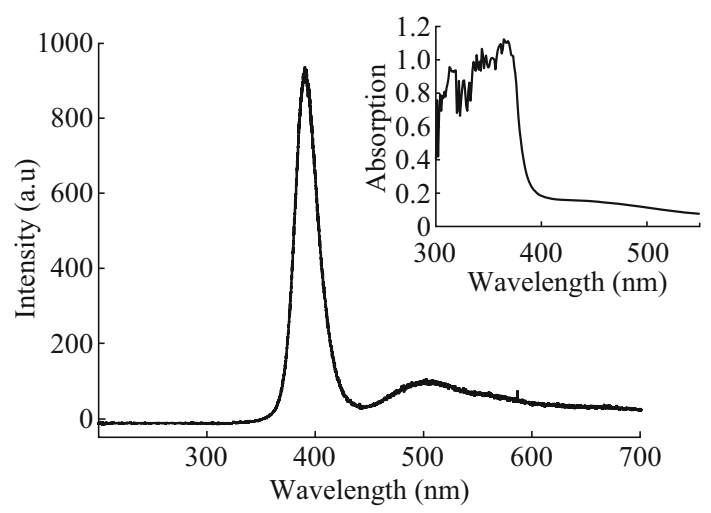

Fig. 4 Room temperature photoluminescence spectrum of the asprepared $\mathrm{ZnO}$ nanosheet film. Excitation wavelength: $325 \mathrm{~nm}$. The inset picture is the UV-Vis absorption spectrum of the same sample

its band gap at nearly $3.25 \mathrm{eV}$. The band-gap values of $\mathrm{ZnO}$ film were calculated by Tauc plot [38, 39].

The photoelectrochemical property of $\mathrm{ZnO}$ nanosheet thin film/ITO electrode was measured with an electrochemical workstation. All PEC measurement was carried out in a mixture solution of $0.35 \mathrm{M} \mathrm{Na}_{2} \mathrm{~S}$ and $0.25 \mathrm{M}$ $\mathrm{Na}_{2} \mathrm{SO}_{3}$ under AM $1.5 \mathrm{G}\left(100 \mathrm{~mW} \mathrm{~cm} \mathrm{~cm}^{-2}\right)$. Figure 5 shows the photoelectrochemical property of $\mathrm{ZnO}$ nanosheet thin film/ITO electrode. Its photocurrent was investigated under a bias voltage of $0 \mathrm{~V}$ (vs. $\mathrm{Ag} / \mathrm{AgCl}$ ) with a light on-off interval of $20 \mathrm{~s}$, as shown in Fig. 5a. All PEC cell exhibits significant photoresponse under a bias voltage of $0 \mathrm{~V}$ (vs. $\mathrm{Ag} / \mathrm{AgCl}$ ), but the sample fabricated at $7.5 \mathrm{mM}$ solution has superior characteristics with a higher photocurrent of $500 \mu \mathrm{A} \mathrm{cm}{ }^{-2}$. The photocurrent density of the photoelectrode varies with the different growth concentrations of $\mathrm{ZnSO}_{4}$ aqueous solution, which may be related to the resistance and surface-to-volume ratio of the samples that could affect the light absorption. Linear sweep voltammograms (LSV) curves were recorded for the $7.5 \mathrm{mM}$ sample in the dark and at $100 \mathrm{~mW} \mathrm{~cm}{ }^{-2}$ (AM 1.5) with a scan rate of $10 \mathrm{mV} \mathrm{s}^{-1}$ in the applied potentials from -1 to $+1 \mathrm{~V}$ (vs. $\mathrm{Ag} / \mathrm{AgCl}$ ), as shown in Fig. 5b. The dark scan shows a very small current density in the range of $10 \mu \mathrm{A} \mathrm{cm}^{-2}$, whereas under light illumination a pronounced photocurrent density was observed, implying
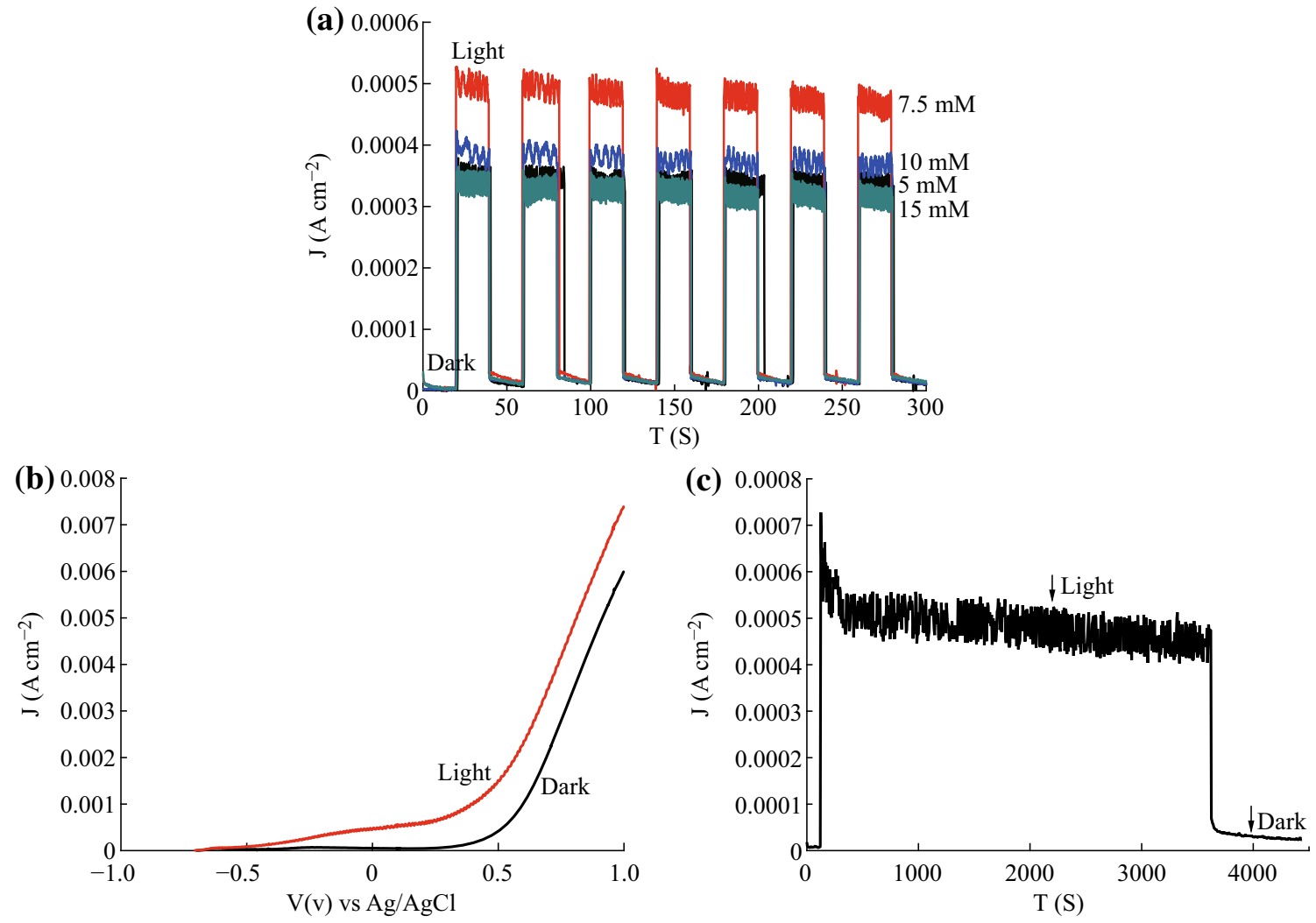

Fig. 5 The photoelectrochemical properties of the $\mathrm{ZnO}$ nanosheet thin film/ITO electrode. a Chronoamperometry measurements at zero bias potential (vs. $\mathrm{Ag} / \mathrm{AgCl}$ electrode) under chopped light illumination with a light on-off interval of $20 \mathrm{~s}$. b LSV curves recorded for the $7.5 \mathrm{mM}$ sample with a scan rate of $10 \mathrm{mV} \mathrm{s}^{-1}$ in the applied potentials from -1 to $+1 \mathrm{~V}$ (vs. Ag/AgCl). c The $J-T$ stability of electrode. All PEC experiments were carried out in a mixture solution of $0.35 \mathrm{M} \mathrm{Na}_{2} \mathrm{~S}$ and $0.25 \mathrm{M} \mathrm{Na}_{2} \mathrm{SO}_{3}$ under AM $1.5 \mathrm{G}\left(100 \mathrm{~mW} \mathrm{~cm}^{-2}\right)$ 


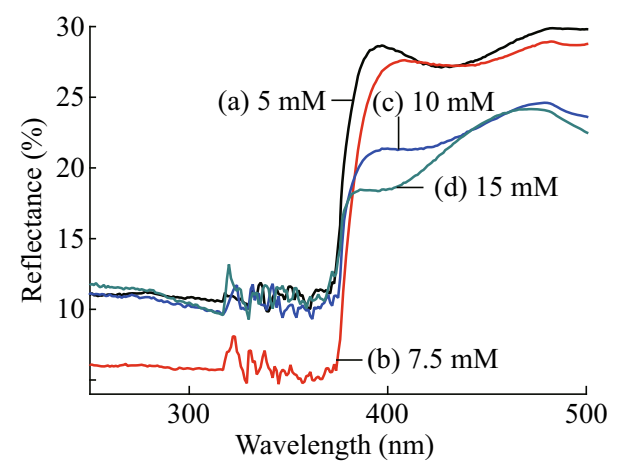

Fig. 6 Reflectance spectra of $\mathrm{ZnO}$ sheet films on ITO glass grown at different concentrations of $\mathrm{ZnSO}_{4}$. $a 5 \mathrm{mM}, b 7.5 \mathrm{mM}, c 10 \mathrm{mM}$, $d 15 \mathrm{mM}$

efficient charge separation and transfer in this nanostructured $\mathrm{ZnO}$. Figure $5 \mathrm{c}$ shows the chronoamperometric plots of the $\mathrm{ZnO} / \mathrm{ITO}$ electrode for about $1 \mathrm{~h}$, which indicated that the photoelectrochemical property was fairly stable under illumination. The photocurrent did not obviously decrease which is very important for the development of practical PEC cells.

In order to further understand the photoelectrochemical property of $\mathrm{ZnO}$ nanosheet films, the UV-Vis reflectance spectra were also measured by PerkinElmer Lambda 950 UV-Vis spectrophotometer. Figure 6 shows the UV-Vis reflection spectra of the $\mathrm{ZnO}$ nanosheet films grown at different concentrations of $\mathrm{ZnSO}_{4}$. It can be seen that the $7.5 \mathrm{mM}$ sample had a maximum ultraviolet absorption compared to other samples. The reflectance spectra result was consistent with the photoelectrochemical result. These results clearly demonstrated that the PEC performance strongly depended on the morphology of $\mathrm{ZnO}$ and could be optimized through controlling the material growth condition.

\section{Conclusion}

In this paper, we had presented a simple and highly efficient solution-based method to prepare large-scale hexagonal $\mathrm{ZnO}$ nanosheet films using a galvanic displacement reaction. The advantages of this solution-processing technique are its simplicity as well as it does not need electric power and supporting agents. The hexagonal $\mathrm{ZnO}$ nanosheet films prepared by this method exhibited excellent PEC properties. These results indicated that the $\mathrm{ZnO}$ nanosheet film could be applied in low-cost, high-performance photoelectrochemical devices or other application fields.

Acknowledgments We were grateful to Linna. Pang for assistance with PL spectrum. This work was supported by the National Major
Basic Research Project of 2012CB934302, the National 863 Program 2011AA050518, and the Natural Science Foundation of China (Grant No. 11174197, 11574203 and 61234005).

Open Access This article is distributed under the terms of the Creative Commons Attribution 4.0 International License (http://crea tivecommons.org/licenses/by/4.0/), which permits unrestricted use, distribution, and reproduction in any medium, provided you give appropriate credit to the original author(s) and the source, provide a link to the Creative Commons license, and indicate if changes were made.

\section{References}

1. S.T. Kochuveedu, Y.H. Jang, D.H. Kim, A study on the mechanism for the interaction of light with noble metal-metal oxide semiconductor nanostructures for various photophysical applications. Chem. Soc. Rev. 42(21), 8467-8493 (2013). doi:10. 1039/c3cs60043b

2. H. Zhou, S.S. Wong, A facile and mild synthesis of 1-D ZnO, $\mathrm{CuO}$, and $\alpha-\mathrm{Fe}_{2} \mathrm{O}_{3}$ nanostructures and nanostructured arrays. ACS Nano 2(5), 944-958 (2008). doi:10.1021/nn700428x

3. E. Comini, C. Baratto, G. Faglia, M. Ferroni, A. Vomiero, G. Sberveglieri, Quasi-one dimensional metal oxide semiconductors: preparation, characterization and application as chemical sensors. Prog. Mater. Sci. 54(1), 1-67 (2009). doi:10.1016/j.pmatsci.2008. 06.003

4. M. Lira-Cantu, F.C. Krebs, Hybrid solar cells based on MEHPPV and thin film semiconductor oxides $\left(\mathrm{TiO}_{2}, \mathrm{Nb}_{2} \mathrm{O}_{5}, \mathrm{ZnO}\right.$, $\mathrm{CeO}_{2}$ and $\mathrm{CeO}_{2}-\mathrm{TiO}_{2}$ ): performance improvement during longtime irradiation. Sol. Energy Mater. Sol. Cells 90(14), 2076-2086 (2006). doi:10.1016/j.solmat.2006.02.007

5. K.T. Park, F. Xia, S.W. Kim, S.B. Kim, T. Song, U. Paik, W.I. Park, Facile synthesis of ultrathin $\mathrm{ZnO}$ nanotubes with well-organized hexagonal nanowalls and sealed layouts: applications for lithium ion battery anodes. J. Phys. Chem. C 117(2), 1037-1043 (2013). doi:10.1021/jp310428r

6. M. Niu, F. Huang, L. Cui, P. Huang, Y. Yu, Y. Wang, Hydrothermal synthesis, structural characteristics, and enhanced photocatalysis of $\mathrm{SnO}_{2} / \alpha-\mathrm{Fe}_{2} \mathrm{O}_{3}$ semiconductor nanoheterostructures. ACS Nano 4(2), 681-688 (2010). doi:10.1021/nn901119a

7. T. Guo, Y. Luo, Y. Zhang, Y.-H. Lin, C.-W. Nan, Controllable growth of $\mathrm{ZnO}$ nanorod arrays on $\mathrm{NiO}$ nanowires and their high UV photoresponse current. Cryst. Growth Des. 14(5), 2329-2334 (2014). doi:10.1021/cg500031t

8. Z.L. Wang, X.Y. Kong, Y. Ding, P. Gao, W.L. Hughes, R. Yang, Y. Zhang, Semiconducting and piezoelectric oxide nanostructures induced by polar surfaces. Adv. Funct. Mater. 14(10), 943-956 (2004). doi:10.1002/adfm.200400180

9. X. Fang, Y. Bando, U.K. Gautam, T. Zhai, H. Zeng, X. Xu, M. Liao, D. Golberg, ZnO and $\mathrm{ZnS}$ nanostructures: ultraviolet-light emitters, lasers, and sensors. Crit. Rev. Solid State 34(3-4), 190-223 (2009). doi:10.1080/10408430903245393

10. Y.Y. Xi, Y.F. Hsu, A.B. Djurišić, W.K. Chan, Electrochemical synthesis of $\mathrm{ZnO}$ nanoporous films at low temperature and their application in dye-sensitized solar cells. J. Electrochem. Soc. 155(9), D595 (2008). doi:10.1149/1.2952519

11. Y. Zhang, J. Xu, Q. Xiang, H. Li, Q. Pan, P. Xu, Brush-like hierarchical $\mathrm{ZnO}$ nanostructures: synthesis, photoluminescence and gas sensor properties. J. Phys. Chem. C 113(9), 3430-3435 (2009). doi:10.1021/jp8092258

12. R. Kumar, O. Al-Dossary, G. Kumar, A. Umar, Zinc oxide nanostructures for $\mathrm{NO}_{2}$ gas-sensor applications: a review. NanoMicro Lett. 7(2), 97-120 (2014). doi:10.1007/s40820-014-0023-3 
13. S. Ho-Kimura, S.J.A. Moniz, J. Tang, I.P. Parkin, A method for synthesis of renewable $\mathrm{Cu}_{2} \mathrm{O}$ junction composite electrodes and their photoelectrochemical properties. ACS Sustain. Chem. Eng. 3(4), 710-717 (2015). doi:10.1021/acssuschemeng.5b00014

14. M. Wu, W.J. Chen, Y.H. Shen, F.Z. Huang, C.H. Li, S.K. Li, In situ growth of matchlike $\mathrm{ZnO} / \mathrm{Au}$ plasmonic heterostructure for enhanced photoelectrochemical water splitting. ACS Appl. Mater. Interf. 6(17), 15052-15060 (2014). doi:10.1021/ am503044f

15. P. Winget, L.K. Schirra, D. Cornil, H. Li, V. Coropceanu et al., Defect-driven interfacial electronic structures at an organic/ metal-oxide semiconductor heterojunction. Adv. Mater. 26(27), 4711-4716 (2014). doi:10.1002/adma.201305351

16. M. Biswas, Y.S. Jung, H.K. Kim, K. Kumar, G.J. Hughes, S. Newcomb, M.O. Henry, E. McGlynn, Microscopic origins of the surface exciton photoluminescence peak in $\mathrm{ZnO}$ nanostructures. Phys. Rev. B 83(23), 235320 (2011). doi:10.1103/PhysRevB.83. 235320

17. Z. Chen, Y. Tang, L. Zhang, L. Luo, Electrodeposited nanoporous $\mathrm{ZnO}$ films exhibiting enhanced performance in dye-sensitized solar cells. Electrochim. Acta 51(26), 5870-5875 (2006). doi:10. 1016/j.electacta.2006.03.026

18. Q. Zhang, C.S. Dandeneau, X. Zhou, G. Cao, ZnO nanostructures for dye-sensitized solar cells. Adv. Mater. 21(41), 4087-4108 (2009). doi:10.1002/adma.200803827

19. A. Saha, C. Jiang, A.A. Martí, Carbon nanotube networks on different platforms. Carbon 79, 1-18 (2014). doi:10.1016/j.car bon.2014.07.060

20. T. Xu, V.A. Davis, Liquid crystalline phase behavior of silica nanorods in dimethyl sulfoxide and water. Langmuir 30(16), 4806-4813 (2014). doi:10.1021/la405013h

21. H. Zhang, W. Ding, K. He, M. Li, Synthesis and characterization of crystalline silicon carbide nanoribbons. Nanoscale Res. Lett. 5(8), 1264-1271 (2010). doi:10.1007/s11671-010-9635-9

22. K. Zhang, S.J. Kim, Y. Zhang, T. Heeg, D.G. Schlom, W. Shen, $\mathrm{X}$. Pan, Epitaxial growth of $\mathrm{ZnO}$ on $\left(\begin{array}{lll}1 & 1 & 1\end{array}\right) \mathrm{Si}$ free of an amorphous interlayer. J. Phys. D-Appl. Phys. 47(10), 105302 (2014). doi:10.1088/0022-3727/47/10/105302

23. R. Kumar, N. Khare, V. Kumar, G.L. Bhalla, Effect of intrinsic stress on the optical properties of nanostructured $\mathrm{ZnO}$ thin films grown by rf magnetron sputtering. Appl. Surf. Sci. 254(20), 6509-6513 (2008). doi:10.1016/j.apsusc.2008.04.012

24. A.-J. Cheng, Y. Tzeng, Y. Zhou, M. Park, T.-H. Wu, C. Shannon, D. Wang, W. Lee, Thermal chemical vapor deposition growth of zinc oxide nanostructures for dye-sensitized solar cell fabrication. Appl. Phys. Lett. 92(9), 092113 (2008). doi:10.1063/1.2889502

25. S. Baruah, J. Dutta, Hydrothermal growth of $\mathrm{ZnO}$ nanostructures. Sci. Technol. Adv. Mater. 10(1), 013001 (2009). doi:10.1088/ 1468-6996/10/1/013001

26. B. O'Regan, V. Sklover, M. Grätzel, Electrochemical deposition of smooth and homogeneously mesoporous $\mathrm{ZnO}$ films from propylene carbonate electrolytes. J. Electrochem. Soc. 148(7), C498 (2001). doi:10.1149/1.1377899
27. H.K. Park, S.P. Hong, Y.R. Do, Vertical growth of $\mathrm{ZnO}$ nanorods prepared on an ITO-coated glass substrate by hydrothermalelectrochemical deposition. J. Electrochem. Soc. 159(6), D355 (2012). doi:10.1149/2.078206jes

28. N.A. Hambali, A.M. Hashim, Synthesis of zinc oxide nanostructures on graphene/glass substrate via electrochemical deposition: effects of potassium chloride and hexamethylenetetramine as supporting reagents. Nano-Micro Lett. 7(4), 317-324 (2015). doi:10.1007/s40820-015-0045-5

29. L. Wang, G. Liu, D. Xue, Effects of introduced electrolytes on galvanic deposition of $\mathrm{ZnO}$ films. Electrochim. Acta 55(22), 6796-6801 (2010). doi:10.1016/j.electacta.2010.05.088

30. S. Nagaya, H. Nishikiori, Preparation of dye-adsorbing $\mathrm{ZnO}$ thin films by electroless deposition and their photoelectrochemical properties. ACS Appl. Mater. Interf. 5(18), 8841-8844 (2013). doi:10.1021/am4026483

31. S. Emin, M. Fanetti, F.F. Abdi, D. Lisjak, M. Valant, R. van de Krol, B. Dam, Photoelectrochemical properties of cadmium chalcogenide-sensitized textured porous zinc oxide plate electrodes. ACS Appl. Mater. Interf. 5(3), 1113-1121 (2013). doi:10. 1021/am3027986

32. A. Goux, T. Pauporté, J. Chivot, D. Lincot, Temperature effects on $\mathrm{ZnO}$ electrodeposition. Electrochim. Acta 50(11), 2239-2248 (2005). doi:10.1016/j.electacta.2004.10.007

33. C. Melis, P. Raiteri, L. Colombo, A. Mattoni, Self-assembling of zinc phthalocyanines on $\mathrm{ZnO}(10 \overline{10})$ surface through multiple time scales. ACS Nano 5(12), 9639-9647 (2011). doi:10.1021/ $\mathrm{nn} 203105 \mathrm{w}$

34. X. Chen, X. Jing, J. Wang, J. Liu, D. Song, L. Liu, Self-assembly of $\mathrm{ZnO}$ nanoparticles into hollow microspheres via a facile solvothermal route and their application as gas sensor. Cryst. Eng. Comm. 15(36), 7243 (2013). doi:10.1039/c3ce40654g

35. U. Özgür, Y.I. Alivov, C. Liu, A. Teke, M.A. Reshchikov, S. Doğan, V. Avrutin, S.J. Cho, H. Morkoç, A comprehensive review of $\mathrm{ZnO}$ materials and devices. J. Appl. Phys. 98(4), 041301 (2005). doi:10.1063/1.1992666

36. L. Wang, G. Liu, L. Zou, D. Xue, Galvanic deposition of $\mathrm{ZnO}$ using mixed electrolyte and their photoluminescence properties. Thin Solid Films 519(15), 4788-4792 (2011). doi:10.1016/j.tsf. 2011.01.073

37. Y. Zhang, H. Jia, R. Wang, C. Chen, X. Luo, D. Yu, C. Lee, Lowtemperature growth and Raman scattering study of vertically aligned $\mathrm{ZnO}$ nanowires on Si substrate. Appl. Phys. Lett. 83(22), 4631 (2003). doi:10.1063/1.1630849

38. C. Persson, C. Platzer-Björkman, J. Malmström, T. Törndahl, M. Edoff, Strong valence-band offset bowing of $\mathrm{ZnO}_{1-\mathrm{x}} \mathrm{S}_{\mathrm{x}}$ enhances p-type nitrogen doping of ZnO-like alloys. Phys. Rev. Lett. 97(14), 146403 (2006). doi:10.1103/PhysRevLett.97.146403

39. T.P. Rao, M.C.S. Kumar, Physical properties of Ga-doped $\mathrm{ZnO}$ thin films by spray pyrolysis. J. Alloys Compd. 506(2), 788-793 (2010). doi:10.1016/j.jallcom.2010.07.071 